\title{
Historical aspects of the traditional development of socio-technical systems
}

\author{
Tatiana Moiseeva, , and Yuri Myatishkin \\ Samara Federal Research Scientific Center RAS, Institute for the Control of Complex Systems RAS, \\ 61, Sadovaya Str., Samara, 443020, Russia
}

\begin{abstract}
The development of socio-technical systems is an important factor determining the state of the country's economy as a whole. There are two possible ways of socio-technical systems development. The first way is traditional development, and the second is innovative one. Traditional development is based on the usual forms of management. It is based on the principles of bureaucratic management, hierarchical structures building, single-handed management decisions-making and responsibility for their implementation. Innovative development is based on new management principles that are fundamentally different from the existing ones. Today the traditional development and management are dominating. In order to understand how to overcome the traditional path of development, it's necessary to study how the traditional management was built in the historical context.
\end{abstract}

\section{Introduction}

Socio-technical systems complies with the need to integrate two types of structures and processes: "technical systems, which are engineered to provide anticipatable and reliable interactions between users and systems, and social systems, which are contingent in their interactions and a subject of evolution" [1]. The development of socio-technical systems can proceed in two directions. It can be traditional development of the socio-technical system or innovative [2]. Traditional development is based on once established forms of management. The changes in it are insignificant and often undesirable. This is not only due to the resistance to change, characteristic of managers at different levels. It is because in most cases, managers are confident that they are using the best management method that satisfies employees and brings profit to the enterprise as a whole.

The innovative development of a socio-technical system means the application of new approaches to management [3]. And we are not talking about any changes being applied to the existing management system. Innovative development is a revolutionary change in the management system of a socio-technical system. The possibility of introducing revolutionary changes into the management system is complicated by the fact that:

- in socio-technical systems, a system of relationships between the control subsystem and the controlled one has already been formed;

\footnotetext{
* Corresponding author: $\underline{\text { mtv-2002@yandex.ru }}$
} 
- there is no generally recognized new approach to management that would transfer socio-technical systems to the path of innovative development.

- Therefore, let's consider how the traditional management system, adopted in most socio-technical systems today, was formed.

\section{Materials and methods}

The materials for this paper are the works of famous scientists in the field of management. The research methods are theoretical analysis and synthesis based on formal logic, and diachronic analysis.

\section{Results and discussion}

\subsection{Evolution of the concept of socio-technical objects management}

The concept of complex socio-technical systems management has undergone significant changes over the long years of their development. However, the main decision-making mechanisms inherent in management theory at the dawn of management are still in use. In order to understand, what is the reason for the lack of positive results in the field of management, it is necessary to trace how the theory of management has evolved (Fig. 1).

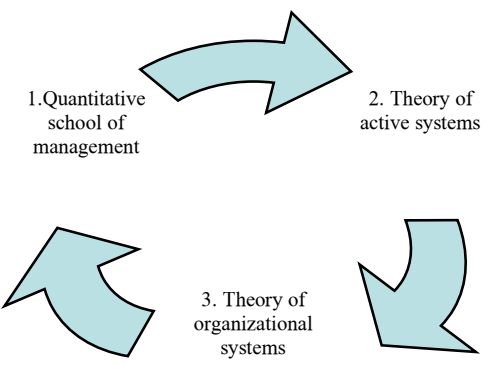

Fig. 1. Evolution of management theory.

According to the principles of classical scientific rationality the place of man is determined to be an element of the world of systems alongside technical devices. The value characteristics of people are not taken into account.

The sixties of the twentieth century were marked by the beginning of information era in management. This period is known as quantitative school of management. The formalization of management theory sought to integrate mathematical analysis and subjective decisions of managers. Management was described as a logical process that can be explained mathematically. Such descriptions were based on the use of mathematical methods (first of all, methods of programming and simulation). The main role in decisionsmaking in management was played by computer technologies.

The systems approach as new direction of methodology of scientific knowledge has also found its application in management. They began to solve problems of socio-technical systems managing on the basis of systems approach. In accordance with the L. von Bertalanffy general theory of systems applied in cybernetics, socio-technical systems were presented as a set of elements (including people) and the connections between them. Adherents of this direction P. Drucker, G. Simon, A. Chandler and others considered socio-technical systems as open systems. Thus, entropy was a measure of their 
disorder, chaos and disorganization. Synergy as the summing effect of the interaction of two or more factors also characterized open socio-technical systems.

These non-closed systems receive different kinds of resources from external environment, process them in their internal world and send finished products backward to the environment. Socio-technical systems exist in permanent interaction with other social, economic, politic, technical and technological elements of environment [4-6]. Mathematical models oriented to formal parameters could explain the actions of the systems. Many textbooks described their behavior with the help of models and formulas. It's wanted to note that the models excluded from the scope of analysis the life world of living subjects. Such persons as the employees of the enterprises producing the products or the consumers ended up overboard and were left out of the study. The main goal of management was defined as the optimization of financial, labor, material or time resources, and not some benefit, which from the point of person's view is the most valuable thing.

It seemed that the ice was broken in the seventies of the twentieth century. People recognized that personal characteristics of people who represented significant part of sociotechnical systems couldn't be left out of consideration. The psychology stood at the forefront of management. The ability of employees to solve problems, assess situations and perceive information occurred to be important in the automated control systems process of creation, implementation and development. The question of the "human factor" in the management system began to play the central role. It was raised since real people who obtained different subjective values were working in the organization. The theory of rationality swayed. The control loop with a subjective element in its structure had to change a decision-making mechanism. Specialists recognized that mathematically rational decision-making didn't lead to optimal management because of people included in humanmachine complexes $[7,8]$.

This time the main directions of scientific work in management have been defined by the role of the subjective component and its influence on management. The scientists dealing with management problems began to study the ways of socio-technical systems improvement. Their work was linked with human factor researches. They began to explore the importance of a person's presence in the management loop. An effulgent flash of understanding of insufficient consideration of the personality in the management system came to specialists. They recognized that management problems are difficult to be solved without taking into consideration people's skills, minds, values and etc. The development of technical means obstructed people's advantages and potential. Their participation in management was reduced, their capabilities stayed not realized. The benefits of technical means, including computers turned out to be less than desirable.

The person itself was perceptible to be the center of the earth of management as a science. Special attention was paid to individual characteristics of person, his will-power, experience, knowledge, capabilities, values, and initiative. A new direction of management science was found, still obscured by the world of systems. Human beings began to be countered as "active elements" of the current man-machine system. It was mentioned that people can have their personal desires, goals and needs. It was marked that these desires, goals and needs they may have independently from the systems in which they fulfil functions of the main elements. Subject's goals do not always coincide with the goals of the system and its management. It became clear that a person may know how to manage but doesn't use his skills in a proper way. He may however try to apply his knowledge slightly and act not in the way that society to which he belongs needs. He may get out of hand. Therefore, specialists in management had to answer the questions of different nature as:

how a social part and technical one can be organized in such a way that the correct distribution of functions between them could reveal a proper management structure, 
- how to make a person to be useful in the management loop of the sociotechnical system,

- how the relationship between social and technical parts of the socio-technical systems can be organized in the proper way.

The answers laid in the sphere of formalization of the human factor. It was proposed to develop the principles of accounting, modelling and formalization of real living people. They also took into account how to use the methods which could help to use person's abilities to work successfully in complex situations in the most effective way. It had been the direction for solving the problem visible that time.

The merit of the Soviet scientist V.N. Burkov is that he developed these ideas. In his works of that period, he introduced the concept of an "active element". He proposed to count the "active element" as a managed object with the property of being active and having its own interests, capable of deliberately transmitting inaccurate information and not realizing what was planned [9]. The role of active elements played people who were interpreted by representatives of this scientific direction and followers as interfering factors. It was supposed that interfering factors can distort information, harm and cripple the system.

These fears determined the goal of management. Its task became to predict distortions in time. If management coped with this task the efficiency of the socio-technical system could withstand its reducing and prevent it. The leaders of the systems had to do the key things. They were responsible for the system's objects, target functions and performance criterium for such system determination. The top managers made their prescriptions based on the observance of the interests of these systems. It was also V.N. Burkov's idea to apply the principle of "open management" which was called by him as "fair play". Its basic provision was "that the plans assigned to the subsystems should be consistent with their performance criterion, which should force the subsystems to communicate their performance criteria honestly" [10].

Such decision-making mechanisms in socio-technical systems endowed employees of organizations with the qualities of unreasonable children. Children obviously can't understand what solution is better for them being coach potatos. This approach corresponded to the definition of a person as a managed object and was warrant in the established conditions. It fully reflected the situation in society and social culture, when the management of social processes was the same as in socio-technical systems.

The situation was crushed in the nineties of the twentieth century. The market economy replaced the Soviet socialist system of economics. So, the main provisions of the theory of active systems were reoriented to the current economic situation. The new theory of organizational systems management [11] was proposed by D.A. Novikov. The focus of D.A. Novikov's theory was on a mathematical theory of management of organizational systems. It was presented, that the purpose of organizational systems was to increase the efficiency of functioning of socio-technical systems and different mathematical methods and means could make the best of a bad bargain. Mathematical modelling once more overshadowed employees of organizations. Person in the management scheme played the role of impersonal element of the system and was considered the projection of living being influenced by a management mechanism. The main function of the employees was seen in execution of orders from superiors, and the art of leader was seen in getting the required by him actions from the subordinates, what was hard nut to crack. The term of "economic agent" occurred in the theory of organizational systems management. A person considered as an economic agent who can deceive everybody if it makes him benefit and suits well and not fulfil what the managers want him to do. A person considered to act in accordance with his own interests and preferences and have a whale of a time. 
Modern management model excludes the role of the subject as an equal participant in the management and decision-making processes. The best-case scenario minimizes its role, even though the essential consideration of the human factor is declared in management science. We don't see any influence of the managed subsystem on the management process which could mend the matters.

The analyses of above sequence of views on management helps to understand the dynamics of the management approaches of socio-technical systems development. It shows how the management and decision-making mechanisms and models adopted in modern society were formed. We think that if nothing is done in improving of subject's role in management than it will make matters worse.

\subsection{Traditional development of socio-technical systems and objects}

It is known that the development of any object or system can be traditional, that is, based on unchanged forms of management that have been used for a long time, or innovative, that is, based on qualitatively new forms of management. This is true for society as a whole and for individual objects of society.

It should be noted that the traditional development of socio-technical is dominant today. A vertical hierarchy of management lays in its basis. According to the principles of ideal bureaucracy all impersonal elements of the organizational system are assigned strictly regulated rules. These rules were formulated and built in management many years ago. They predict every element how it must work. Maintaining in a working condition and optimizing the created structure for managing social and technical processes, providing the existence of officials themselves in it is above all things. This is the major goal and the key interest of the system. Managers are the ones who rank problem situations and make decisions, what to do and in what sequence. They grant people the right to external monitoring of the problems, but in no case, it means that ordinary people can influence the activities of a bureaucratic organization. People doesn't take part in setting tasks, formulating the problems and identifying their ranges. They don't define the problems which solutions require high or low priority of intervention.

Dissatisfaction with many points of traditional management lead to some attempts to transform it into innovative one. But they are targeted on slight repair of the management system, usually associated with insignificant changes. Unfortunately, all reconstructions are targeting insufficient things. They do not affect the main principles of management decisions making. Managers are afraid to involve people in decision-making process and destroy well-established system. It is fundamentally wrong, because these activities' missile is improving of people's lives and it is logical for them to take part in the processes. Otherwise they couldn't be satisfied by it. In fact, the principles of an ideal bureaucracy contribute to the creation of a multi-level pyramid of power. Its drawback is that it places at the top of the hierarchy the manager. His role and functions in the system are absolutized. But it is nonsense because manager does not always understand the meaning of the problem, due to his indirect involvement in it. By the way, that is why he doesn't see the possible and proper path to find the result. This situation is characterized by a centralized closed decision-making at the top of governing pyramid. It ignores the context and environment of the situation, the personal qualities and values of each participant of the problem situation, their needs and desires, etc. There is no need to talk about an innovative approach in this case.

The established traditions created modern approach to management. It is based on established principles when the role of a person in manufacturing of goods was determined only by his invariable physical strength and was limited by the laws of mechanics. In social everyday life public morality encouraged the restriction of changes, i.e. immutability of a 
person's family position, his permanent lifestyle, invariable profession, constant worldview, etc. Modeling the processes of optimal human-machine interaction hiding the identity and individuality of the person served in a bad way. The trap of technological determinism arosed, which is characterized by not taking into account very important facts as the diversity of life situations and the social effects of the spread of technology. The current situation brakes new innovative approaches to management and makes it difficult to find and implement them [12]. However, understanding the reasons for the dominance of the traditional approach to management, identified in this article as the result of historical analysis, is the first step towards the innovative development of socio-technical systems.

\section{Conclusions}

1. The development of socio-technical systems today is carefully analyzed not only by managers, but also by theorists in the field of management.

2. Analysis of possible options for the development of socio-technical systems shows that two options for development are possible: traditional and innovative.

3. Traditional development is based on the established forms of management, based on a vertical hierarchy of management. According to the principles of ideal bureaucracy all impersonal elements of the organizational system are assigned strictly regulated rules. They predict every element how it must work. The key interest of the system is to get alive themselves. Decision-making takes place in a closed way, in the upper echelons of power.

4. The innovative development of the socio-technical system means the application of new approaches to management, different from those used today.

5. The dominant type of management in modern socio-technical systems is traditional management, which determines their development. The main distinguishing feature of such management is the weak use of the subjective value characteristics of people. The task of management theory today is to find and substantiate new ways of socio-technical systems development.

The paper was prepared according to the plan of research work of Samara Federal Research Scientific Center RAS, Institute for the Control of Complex Systems RAS, theme No. AAAA-A19119030190053-2.

\section{References}

1. G. Fischer, T. Herrmann, International J. of Sociotechnology and Knowledge Develop ment, 3(1), 1 (2011)

2. T. V. Moiseeva, Proceeding of the International Science and Technology Conference "FarEastCon 2019", 267 (2019)

3. T.V. Moiseeva, S.V. Smirnov, Studies in Systems, Decision and Control, 199, 15 (2019)

4. P. F. Drucker, The Management Challenge for the 21st Century (1999)

5. A. D. Chandler, Strategy and Structure: Chapters in the History of the Industrial Enter prise (1962)

6. H. A. Simon, Theories of Decision-Making in Economics and Behavioural Science (1996)

7. A. Cherns, Human Relations, 2(9), 783 (1976)

8. C.W. Clegg, Applied Ergonomics, 31, 463 (2000) 
9. V. N. Burkov, A.K. Enaleev, V.V. Kondrat'ev, A.V. Tsvetkov, Automation and remote control, 10, 1356 (1983)

10. V. N. Burkov, A. Ya. Lerner, Fairplay in Control of Active Systems (1971)

11. V. Burkov, M. Goubko, N. Korgin, D. Novikov, Introduction to Theory of Control in Organizations (2015)

12. R.E. Lucas, J. Monet. Econ., 1(22), 3 (1988) 